\title{
A EDUCAÇÃo EM SAÚdE REALIZADA EM GRUPOS COM OBESIDADE ABORDADA PELA EQUIPE MULTIPROFISSIONAL EM COLOMBO-PR
}

Carla Vanessa Alves LOPES, Juliana Balbi de OLIVEIRA, Ana Eliza Santos FURLANETTO, Marilene BUFFON, Giovana PECHARKI

A obesidade é um problema de saúde pública, devido sua alta incidência e prevalência, por isso a atenção primária à saúde deve ser resolutiva para alcançar a promoção da saúde e prevenção da obesidade e redução do peso. O objetivo deste estudo é relatar a experiência da equipe de residentes multiprofissional em Saúde da Família, na Unidade de Saúde (U.S) Jardim das Graças sobre o processo de educação em saúde com um grupo de crianças e adolescentes obesos identificados nas consultas com a nutricionista residente. Com vistas às ações de educação em saúde multiprofissional, a equipe de saúde formou um grupo com reuniões mensais, o qual se reúne no Centro de Convivência próximo à U.S. para trocar experiências sobre alimentação saudável junto à Nutricionista. A odontologia aborda a prevenção de cáries e doenças periodontais, orientando sobre o uso racional do açúcar e incentivando a higiene bucal. A farmacêutica aborda a medicação para perda de peso: indicações e contra-indicações, e a medicina e enfermagem ainda serão incluídas no grupo. Percebe-se assim, que a educação em saúde no grupo não está somente focada na doença (obesidade), apontando como principal foco a qualidade de vida do usuário inserido no meio (família e comunidade).

Palavras-chave: Educação em Saúde; Saúde da Família; Obesidade. 